\title{
Association of tetra-amelia, ectodermal dysplasia, hypoplastic lacrimal ducts and sacs opening towards the exterior, peculiar face, and developmental retardation
}

\author{
SHOZO OHDO*, HARUMICHI MADOKORO*, TOHRU SONODA*, \\ MANABU TAKEI*, HIROSHI YASUDA $\dagger$, AND NORIMASA MORI $\dagger$ \\ From the Departments of Pediatrics* and Obstetrics and Gynecology†, Miyazaki Medical College, 5,200 \\ Kihara, Kiyotake-cho, Miyazaki 889-16, Japan.
}

SUMmARY A male child with tetra-amelia, hypotrichosis, upward slanting palpebral fissures, lack of lacrimal openings, hypoplastic lacrimal ducts and sacs opening towards the exterior, prominent and bulbous nose, large downturned mouth, high narrow palate, bilateral preauricular pits, sacral dimple, bilateral undescended testes, and developmental retardation is reported. The parents were second cousins. His karyotype on cultured blood lymphocytes was normal. Since the next fetus conceived by the mother was found on prenatal ultrasonography to have no limbs, abortion was induced. The face of the abortus closely resembled that of the proband. It is postulated that this malformation syndrome was due to the homozygous state of a rare autosomal recessive mutation.

Tetra-amelia is a very rare congenital anomaly ${ }^{1}$ often found with associated abnormalities. ${ }^{2-4}$ However, we were unable to find reports of patients with constellations of features similar to those present in the patients described in this paper.

\section{Case reports}

\section{CASE 1}

The proband was born on 3.2.85, the second child of healthy parents. The father was 35 years old and the mother 26. They were second cousins. The mother had had one induced abortion. The older sister was healthy. There was no family history of limb deficiencies.

Pregnancy was unremarkable and delivery at 39 weeks was spontaneous. At birth, the presentation was breech. The Apgar score was 9. Birth weight was $1864 \mathrm{~g}$, height (crown to rump) $27.0 \mathrm{~cm}$, and head circumference $35 \cdot 0 \mathrm{~cm}$. Since major malformations were present, he was referred to our outpatient clinic on the day of birth. On physical examination, the left upper limb and both lower limbs were completely absent, while a trace of the right upper limb was recognisable (fig 1). Hair on the head and eyebrows were completely absent and eyelashes were sparse. Palpebral fissures were upward slanting. There were no lacrimal openings and lacrimal ducts and sacs were hypoplastic, opening towards the exterior. The nose was prominent and bulbous, the mouth was big and downturned, and a high, narrow palate was present (fig 2). There were preauricular pits on both sides, and an umbilical hernia and sacral dimple. There was no heart murmur. The external genitalia were that of a normal male with bilateral undescended testes.

$X$ rays showed the right humerus to be about $3 \mathrm{~cm}$ long, but the bones of the left upper limb and both lower limbs were completely absent. The right clavicle was hypoplastic (fig 3). ECG was normal. No sweating abnormalities were manifested. Chromosome analysis revealed a normal male karyotype and there was no centromeric abnormality of the chromosomes. Laboratory tests, including electrolytes, immunoglobulin, T3 and T4 levels, and urine analysis, were normal.

During the first year, he had frequent middle grade fevers, without any findings of infection. At one year his height (crown to rump) was $44.0 \mathrm{~cm}$, weight $6170 \mathrm{~g}$, and head circumference $46.5 \mathrm{~cm}$ 


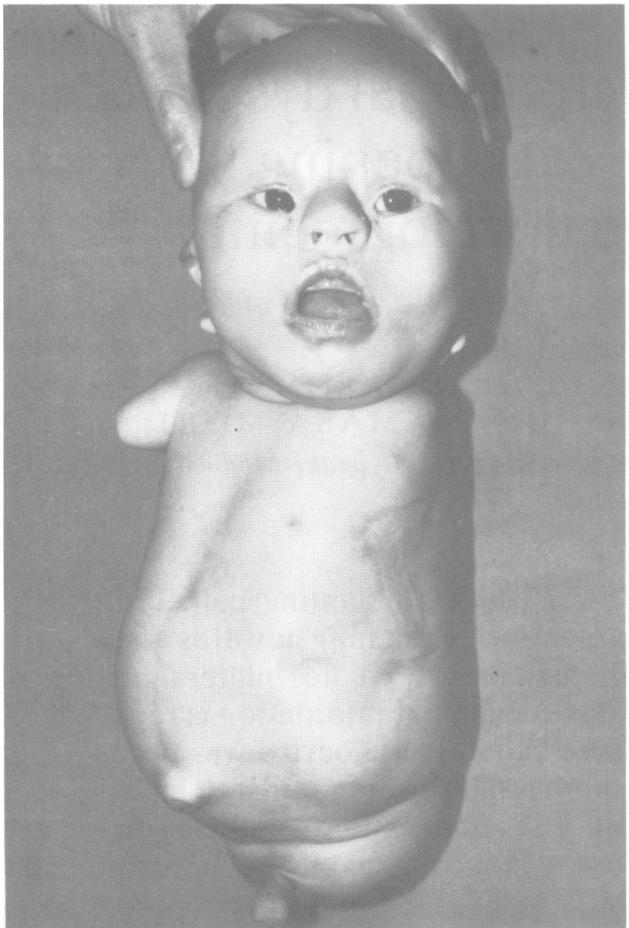

FIG 1 The proband 17 days after birth.

(average). At that time he had five teeth and fine, sparse hair on his head. Developmental quotient was about 20.

\section{CASE 2}

The parents were told that since they were second cousins, it was imperative that any future fetus be examined prenatally. Shortly thereafter the mother conceived. Echographic prenatal diagnosis of the fetus was done at 16 weeks of gestation, with neither the upper nor lower limbs of the fetus being recognisable. The parents were informed of these findings and chose to have the pregnancy terminated. Labour was induced at 20 weeks of gestation with vaginal suppositories of 16,16 -dimethyl-trans$\Delta^{2}$ prostaglandin $\mathrm{E}_{1}$.

The abortus was female. Height (crown to rump) was $19.5 \mathrm{~cm}$, weight $400 \mathrm{~g}$, and head circumference $20 \cdot 2 \mathrm{~cm}$. The limbs were completely absent (fig 4). Her face looked very much like that of the proband. There were no lacrimal openings and the lacrimal ducts and sacs were hypoplastic and opened towards the exterior. She had a large mouth and a preauricular pit on the right side. A sacral dimple was not noted. At necropsy, no major visceral abnormality was found.

\section{Discussion}

Cases involving limb deficiencies are not rare. The frequency of limb reduction defects estimated in Finland by Aro was 5.0 per 10000 births. ${ }^{5}$ How- $\frac{\widehat{\sigma}}{\bar{D}}$ ever, tetra-amelia is extremely rare. ${ }^{1-46}$ Since the $\varrho$ frequency of stillbirth ${ }^{7}$ or early death during the newborn period ${ }^{2-5}$ is high in these cases, it is $\vec{\circ}$ probable that not all cases with tetra-amelia have $\stackrel{-}{-}$ been reported.

In many cases limb deficiencies are associated with other malformations ${ }^{2-589}$ and limb deficiencies are sometimes recognised as a part of variousis other malformation syndromes. ${ }^{10}$ The characteris- + tics of the two cases reported here are as follows: (1) $\overrightarrow{0}$ complete or almost complete tetra-amelia, (2) hypotrichosis, (3) peculiar face, (4) ocular abnorma- 6 lities, and (5) developmental retardation.

인

Roberts syndrome has an association of $-\overrightarrow{-}$ hypomelia, microcephaly, cleft lip with or without? cleft palate, hypotrichosis, facial haemangioma, andö severe growth deficiency. ${ }^{11}$ The cases reported by@ Freire-Maia in 1970 had tetramelic deficiencies, $\rightarrow$ ectodermal dysplasia, mental retardation, hypogo- $\infty$

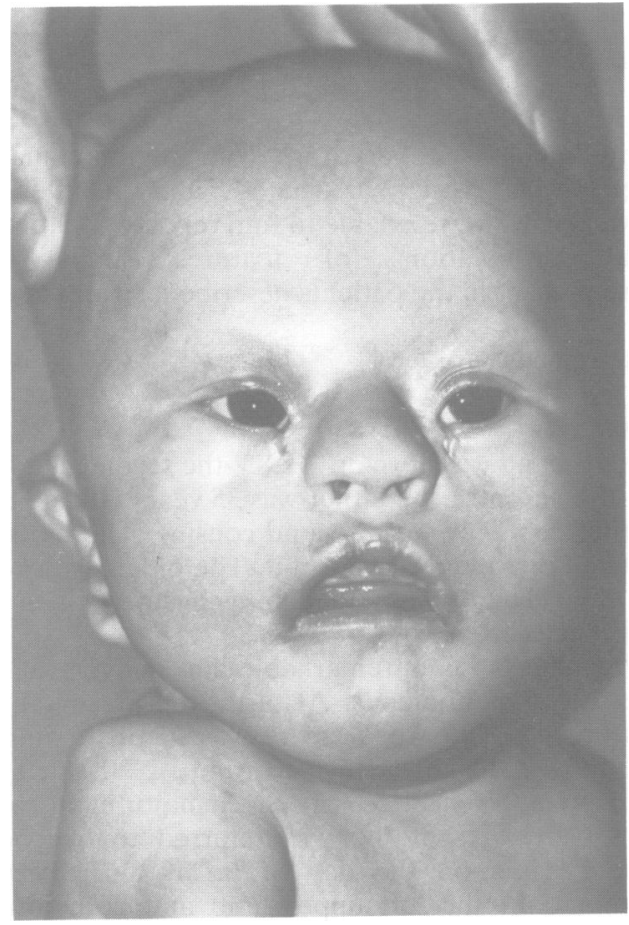

FIG 2 Facial appearance of the proband. Note hypotrichosis, ocular abnormalities, prominent and bulbous nose, and large mouth. 


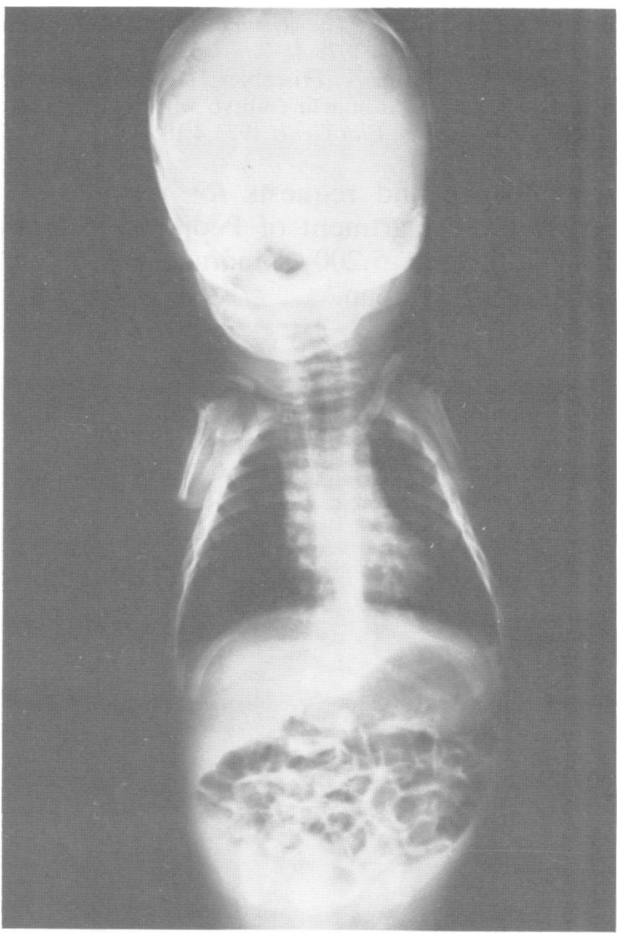

FIG $3 X$ ray of the proband. Note absence of the inner half of the right clavicle.

nadism, abnormality of tyrosine with or without tryptophane metabolism, and many other anomalies. ${ }^{9}$ In cases of Roberts syndrome and the cases reported by Freire-Maia, however, the degree of limb deficiency was milder than that in our cases and without the accompanying peculiar face. Moreover, a centromeric abnormality of the chromosomes, namely, puffing and splitting, ${ }^{12}$ was absent in our cases.

The aetiology of most limb deficiencies in man is unknown, but a few of these conditions are due to autosomal dominant or recessive mutation. ${ }^{9}$ The Brazilian type of acheiropodia is known to be an aucosomal recessively inherited disease. ${ }^{13}$ Generally speaking, however, a significant family history in cases with limb deficiency is rare ${ }^{814}$ and parental consanguinity is infrequent. ${ }^{10}$ Only a few cases are caused by a predominantly exogenous mechanism (thalidomide, Tigan, ${ }^{14}$ maternal diabetes, etc). Recognised syndromes, such as Cornelia de Lange syndrome, or chromosomal aberrations ${ }^{15}$ sometimes also include limb deficiency.

Since the parents of the cases reported in this paper were second cousins, the malformation syn-

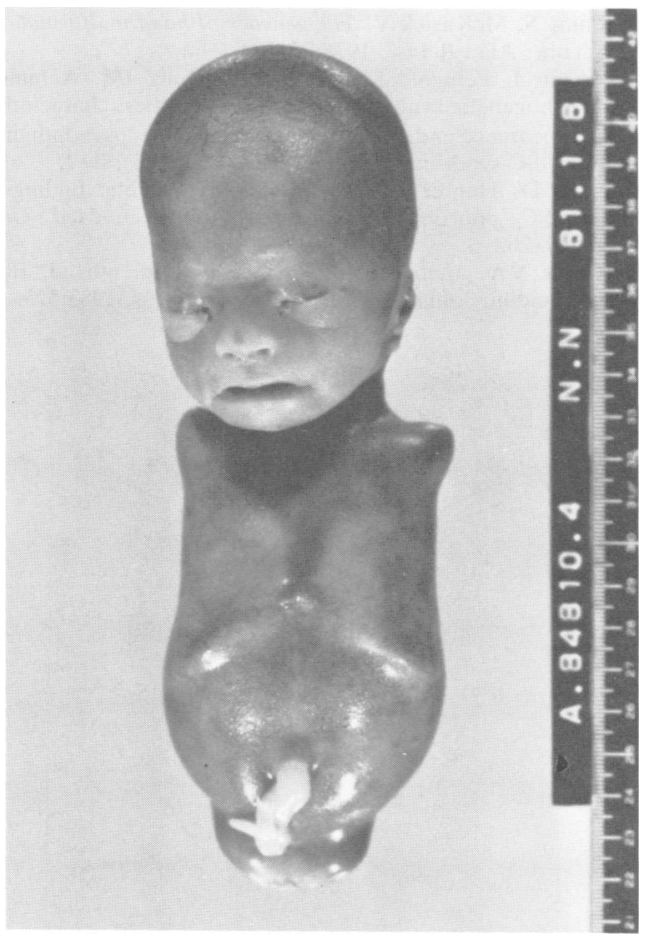

FIG 4 Clinical appearance of the abortus.

drome reported here may be caused by the homozygous state of a rare autosomal recessive mutation.

\section{References}

1 Warkany J. Congenital malformations. Notes and comments. Chicago: Year Book Medical Publishers, 1971: 947-57.

2 Frantz $\mathrm{CH}$, O'Rahlly R. Congenital skeletal limb deficiencies. J Bone Joint Surg (Am) 1961:43:1202-24.

${ }^{3}$ Dresher CS, Macdonell JA. Total amelia. J Bone Joint Surg (Am) 1965:47:511-6.

+ Zimmer EZ, Taub E, Sova Y, et al. Tetra-amelia with multiple malformations in six male fetuses of one kindred. Eur J Pediatr 1985:144:412-4.

5 Aro T. Reduction limb defects in Finland. In: Marois M, ed. Prevention of physical and mental congenital defects. Part $\mathrm{C}$. Basic and medical science, education, and future strategies. New York: Alan R Liss, 1985:95-7.

${ }^{6}$ Poidevin LOS. Amclia. Review of the literature and report of a case. J Obstet Gynaecol Br Empire 1953;60:922-5.

7 Garcia Otero RG. Un caso de 'amelio'. Rev Clin Esp 1944:12:117-24.

${ }^{8}$ Hall CB, Brooks MB, Dennis JF. Congenital skeletal deficiencies of the extremities. JAMA 1962;181:590-9.

${ }^{9}$ Freire-Maia N. A newly recognized genetic syndrome of tetramelic deficiencies, ectodermal dysplasia, deformed ears, and other abnormalities. Am J Hum Genet 1970;22:370-7. 
16 Temtamy S, McKusick V. The genetics of hand malformations. New York: Alan R Liss, 1978:73-184.

"Herrmann J, Feingold M, Tuffli GA, Opitz JM. A familial dysmorphogenetic syndrome of limb deformities, characteristic facial appearance and associated anomalies: the 'pseudothalidomide' or 'SC-syndrome'. Birth Defects 1969;V(3):81-9.

12 Tomkins D, Hunter A, Roberts M. Cytogenetic findings in Roberts-SC phocomelia syndrome(s). Am J Med Genet 1979;4:17-26.

13 McKusick VA. Mendelian inheritance in man. 6th ed. Baltimore, London: Johns Hopkins University Press, 1983:575.
${ }^{14}$ Temtamy S, McKusick V. The genetics of hand malformations. New York: Alan R Liss, 1978:41-3

15 Pawlowitzki IH, Cenani A, Frischbier HJ. Autosomal monosomy $(45, \mathrm{XX}, \mathrm{C}-)$ in a human embryo with total amelia and further malformations. Clin Genet 1973;4:193-202.

Correspondence and requests for reprints to $\mathrm{Dr} \stackrel{\mathbb{\mathrm { D }}}{\Omega}$ Shozo Ohdo, Department of Pediatrics, Miyazaki ڤ Medical College, 5,200 Kihara, Kiyotake-cho, Miyazaki 889-16, Japan.

.

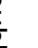

